\title{
Generation and expansion of multipotent mesenchymal progenitor cells from cultured human pancreatic islets
}

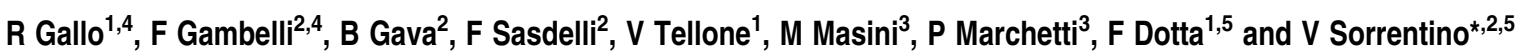

Cellular models and culture conditions for in vitro expansion of insulin-producing cells represent a key element to develop cell therapy for diabetes. Initial evidence that human $\beta$-cells could be expanded after undergoing a reversible epithelialmesenchymal transition has been recently negated by genetic lineage tracing studies in mice. Here, we report that culturing human pancreatic islets in the presence of serum resulted in the emergence of a population of nestin-positive cells. These proliferating cells were mainly C-peptide negative, although in the first week in culture, proliferating cells, insulin promoter factor-1 (Ipf-1) positive, were observed. Later passages of islet-derived cells were Ipf-1 negative and displayed a mesenchymal phenotype. These human pancreatic islet-derived mesenchymal (hPIDM) cells were expanded up to $10^{14}$ cells and were able to differentiate toward adipocytes, osteocytes and chondrocytes, similarly to mesenchymal stem/precursor cells. Interestingly, however, under serum-free conditions, hPIDM cells lost the mesenchymal phenotype, formed islet-like clusters (ILCs) and were able to produce and secrete insulin. These data suggest that, although these cells are likely to result from preexisting mesenchymal cells rather than $\beta$-cells, hPIDM cells represent a valuable model for further developments toward future replacement therapy in diabetes.

Cell Death and Differentiation (2007) 14, 1860-1871; doi:10.1038/sj.cdd.4402199; published online 6 July 2007

Type 1 diabetes mellitus is a chronic disease resulting from the selective autoimmune destruction of pancreatic insulinproducing $\beta$-cells. Transplantation therapy represents a potential cure for type 1 diabetes mellitus, ${ }^{1}$ but is limited by availability of human pancreatic tissue. For this reason, a great effort has been made to develop new methods for generating $\beta$-like cells in vitro, ${ }^{2,3}$ despite of evidence that cultured $\beta$-cells have limited proliferative capacity and reduced insulin production. ${ }^{4}$ Several attempts have been made to identify stem/progenitors cells within pancreatic tissue as a potential source for transplantable insulinproducing tissue. Unfortunately, the origin of new $\beta$-cells in adult pancreas is not known. Some in vivo studies suggested the presence of pancreatic progenitor cells within islets, ${ }^{5}$ whereas others reported that new adult $\beta$-cells might rather originate from pre-existing $\beta$-cells. ${ }^{6}$ Additional studies suggested that progenitor cells may reside within the pancreatic ductal epithelium ${ }^{2-7}$ or in the acinar tissue..$^{8,9}$ Nevertheless, the exact nature and localization of adult pancreatic stem/ progenitor cells remains controversial ${ }^{9-16}$ and their existence in vivo, at least in mice, has recently been questioned. ${ }^{6}$ Recent evidence has shown that human embryonic stem cells are able to differentiate into insulin-producing cells in vitro, thus potentially leading to an unlimited source of cells for transplantation. ${ }^{17,18}$ Some of these studies have noted that cultured islet cells may express nestin, an intermediate filament expressed in several precursor/stem cells. ${ }^{10-12}$ The association of nestin-positive cells with human pancreatic islets is of interest in light of evidence that nestin expression precedes the appearance of $\beta$-cells during embryogenesis. ${ }^{13}$ In addition, although no direct origin of $\beta$-cells from nestinpositive cells has been demonstrated in postnatal life, ${ }^{14}$ recent reports have shown that nestin-positive progenitor cells isolated from human fetal pancreas may have phenotypic markers identical to mesenchymal stem cells and are able to proliferate and differentiate into insulin-producing cells

\footnotetext{
${ }^{1}$ Diabetes Unit, Department of Internal Medicine, Endocrine and Metabolic Sciences and Biochemistry, University of Siena, Siena, Italy; ${ }^{2}$ Molecular Medicine Section, Department of Neuroscience and Center for Stem Cell Research, University of Siena, Siena, Italy and ${ }^{3}$ Metabolic Unit, Department of Endocrinology and Metabolism, University of Pisa, Italy

${ }^{*}$ Corresponding author: V Sorrentino, Molecular Medicine Section, Department of Neuroscience, University of Siena, via A. Moro, Siena 53100, Italy.

Tel: + 390577234 079; Fax: + 390577234 191; E-mail: v.sorrentino@unisi.it

${ }^{4}$ These two authors contributed equally to this work.

${ }^{5}$ These two authors share senior authorship.

Keywords: $\beta$-cells; mesenchymal progenitor cells; pancreatic islets; diabetes

Abbreviations: ABCG2, ATP-binding cassette sub-family G member 2; aFABP, adipocyte fatty acid binding protein; AP, alkaline phosphatase; BrdU, 5-bromo2'deoxyuridine; BSA, bovine serum albumin; CBFA-1, core binding factor alpha 1; FACS, fluorescence-activated cell sorting; FBS, fetal bovine serum; GAPDH, glyceraldehyde-3-phosphate dehydrogenase; GFP, green fluorescent protein; GLUT-2, glucose transporter-2; GM, growth medium; hPIDM, human pancreatic isletderived mesenchymal; HPRT, hypoxanthine guanine phosphoribosyl transferase; hTERT, human telomerase reverse transcriptase; ILCs, islet-like clusters; Ipf-1, insulin promoter factor-1; ISL-1, islet-1; NEUROD1, neurogenic differentiation 1; NKX2-2, NK2 transcription factor-related locus2; NKX6-1, NK6 transcription factor related locus1; PC1, 3, prohormone convertase 1, 3; PPAR $\gamma 2$, peroxisome proliferator-activated receptor $\gamma 2 ; \alpha$-SMA, $\alpha$-smooth muscle actin

Received 18.12.06; revised 05.6.07; accepted 07.6.07; Edited by RA Knight; published online 06.7.07
} 
in vitro. ${ }^{15}$ However, controversial data on the ability of mesenchymal stem cells to differentiate into insulin-producing cells both in vitro and in vivo have been reported. ${ }^{19-23}$ Major interest has been recently raised by the evidence that insulinproducing cells can be obtained following the in vitro expansion of an intermediate mesenchymal proliferating cell population apparently derived from a reversible epithelialmesenchymal transition of pancreatic $\beta$-cells. ${ }^{24,25}$ Similar results have been obtained from the exocrine compartment of human pancreas. ${ }^{26}$ However, several groups have recently provided evidence, based on cell-lineage tracing experiments in mouse, that mesenchymal cells from pancreatic islets do not originate by an epithelial-mesenchymal transition from $\beta$-cells, but may derive from a population of pre-existing connective tissue mesenchymal cells associated with pancreatic epithelial structures. ${ }^{27-31}$

Here, we report results from experiments aimed at the characterization of human pancreatic islet-derived mesenchymal (hPIDM) cells. These results provide clear evidence that, in the presence of fetal bovine serum (FBS), cultures of purified adult human pancreatic islets can generate an intermediate mixed cell population from which mesenchymal cells positive for nestin can be reproducibly obtained. These cells can be expanded for 16-20 passages and can differentiate toward mesenchymal lineages, such as adipocytes, osteocytes and chondrocytes, as observed for mesenchymal stem/precursor cells. Interestingly, on serum removal, these cells lose their mesenchymal phenotype and differentiate into islet-like clusters (ILCs) and secrete insulin.

\section{Results}

Isolation and expansion of proliferating cells from human pancreatic islets. Human pancreatic islet-enriched fractions were placed in plastic tissue culture dishes in RPMI 1640 supplemented with $10 \%$ FBS, at approximately 1 islet/ $\mathrm{cm}^{2}$. As shown in Figure 1a, within $24 \mathrm{~h}$ all islets attached to the surface of the dishes. During the following days, the islets changed their original three-dimensional architecture and acquired a morphology with a central 'core' of aggregated cells surrounded at the periphery by a migrating population of flattened epithelial cells. After 14 days in culture, cells were trypsinized and transferred to new tissue culture dishes. The vast majority of the cells adhered to the new dishes, proliferated and, when grown to near confluence, the monolayer cells were subcultured again. During the first passage, the cell population displayed a progressive change in morphology from epithelial to fibroblast-like cells (Figure 1a). After the first three passages, the cells were subcultured every 8 days by plating 4000 cells $/ \mathrm{cm}^{2}$. The cells presented an average population doubling time of about 6 days and were maintained in culture for up to 20 passages for a total period of about 180 days (Figure 1b). According to
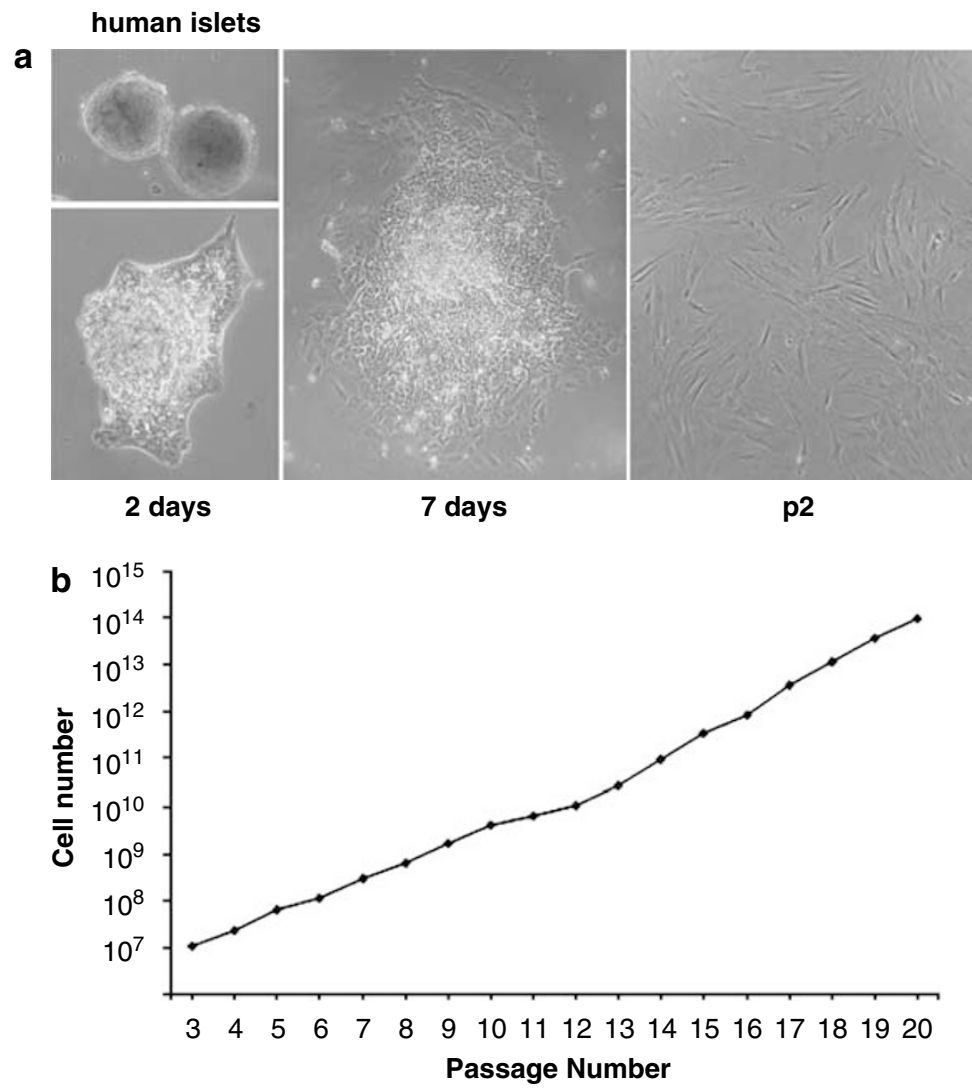

Figure 1 Human pancreatic islet-derived cells in culture. (a) Phase contrast microscopy of free-floating human islets; 2- and 7-day-old islet cultures; hPIDM cells at passage 2 (p2). (b) Representative growth curve of hPIDM cells 
this protocol, starting from about 250 islet equivalents, we could expand hPIDM cells to a population of $10^{12}-10^{14}$ cells before the cultures started to become quiescent, which occurred between 12 and 20 population doublings.

\section{Characterization of human pancreatic islet-derived} proliferating cells. To characterize the phenotype of proliferating cells emerging from cultured human pancreatic islets, the expression of C-peptide (a $\beta$-cell marker corresponding to a region of the proinsulin peptide), Ipf-1 (a transcription factor expressed in $\beta$-cells), nestin (an intermediate filament protein expressed by neuroepithelial and muscular progenitors), $\alpha$-smooth muscle actin ( $\alpha$-SMA) and vimentin (both mesenchymal cell markers) were determined by immunofluorescence analysis. Parallel staining for Ki67 and 5-bromo-2'deoxyuridine (BrdU) was performed to verify the proliferative status of cultured cells.

As shown in Figure $2 \mathrm{a}$, cells of human pancreatic islets cultured for one and half day were positive for C-peptide and negative for Ki67. Between 3 and 6 days in culture, the majority of cells exhibited a gradual reduction in C-peptide staining, whereas Ki67-positive cells started to emerge (Figure 2a). The vast majority of Ki67-positive cells were C-peptide-negative (arrowheads), whereas cells positive for both C-peptide and Ki67 were rare (arrows). Cultured islets after one and half day did not express nestin, whereas between days 3 and 6 of culture, nestin-positive cells started to be detected (Figure 2b). At day 3, between 5 and $10 \%$ of the cells positive for C-peptide were also nestin-positive (Figure 2b, arrows). A similar number of cells were positive for nestin but negative for C-peptide (arrowheads). No cell strongly positive for C-peptide was positive for nestin. Ipf-1, another marker of pancreatic endocrine cells, was expressed in $20-30 \%$ of islet cells after 3 days of culture. Double staining of cells for Ipf-1 and for Ki67 indicated that, depending on the islet preparation, up to $40 \%$ of cells positive for Ipf-1 were proliferating (Figure 2c, arrows). Ipf-1-positive cells represented approximately $30 \%$ of all Ki67-positive cells, indicating that additional proliferating cells negative for Ipf-1 were also present (arrowheads). As shown in Figure 2d, 20\% of Ipf-1expressing cells were also positive for nestin (arrows), whereas other nestin-positive cells were negative for Ipf-1 (arrowheads).

Staining with $\mathrm{Ki67}$ revealed that proliferating cells in 3-dayold cultures represented between 2 and $10 \%$ of total cells and that an average about $25 \%$ of the proliferating cells were nestin-positive (Figure 2e, arrows). The rate of proliferation of cultured islet cells was further evaluated after BrdU incorporation for $72 \mathrm{~h}$. The percentage of BrdU-labeled cells in 3-dayold islet cultures was about $2 \%$ (data not shown), whereas in 6-day-old islet cultures, the percentage of proliferating cells increased to $5 \%$ (Figure 2e). Double immunostaining for BrdU and nestin in 6-day-old islet cultures showed that approximately $50 \%$ of replicating cells were nestin-positive (Figure 2e, arrows). Nevertheless, both BrdU and Ki67 staining revealed that whereas some nestin cells were proliferating (arrows) others were not (arrowheads). Analysis of the expression of $\alpha$-SMA indicated that during the first week of culture, $\alpha$-SMA was undetectable in islet-derived cells (data not shown), whereas a strong expression of this protein was observed after the first week of culture (Figure 3a). At this time, vimentin, another intermediate filament protein of mesenchymal cells, was also detected in virtually all cells, where it was coexpressed with $\alpha$-SMA and with nestin (Figure 3a and b).

Flow cytometry experiments and real-time PCR analysis reveal a decrease in pancreatic endocrine genes and an increase in the expression of mesenchymal genes in hPIDM cells. Real-time PCR analysis performed on hPIDM cells, revealed the expression of mesenchymal gene markers such $\alpha$-SMA, vimentin, twist, snail1, snail2, CD73 and CD105 (Figure 4a), accompanied by a major downregulation of pancreatic endocrine gene markers such as insulin, glucagon, somatostatin, prohormone convertase 1 (PC1), glucose transporter-2 (GLUT-2), glucokinase, synaptophysin, Ipf-1, islet-1 (ISL-1), NK2 transcription factor-related locus2 (NKX2-2), NK6 transcription factorrelated locus1 (NKX6-1) and neurogenic differentiation 1 (NEUROD1), (Figure 4b). In parallel, fluorescence-activated cell sorting (FACS) experiments were performed to define the cell surface antigen profile of hPIDM cells at passages 8 , 12 and 18. Cells were negative for hematopoietic markers such as CD45, CD34, CD14 and endothelial antigens like CD106 and CD31, but were positive for mesenchymal (CD44, CD90 and CD13) and stem cell markers (CD105 and CD73), (Table 1 and Figure 4c). In addition, they expressed low levels of stromal-derived factor-1 (STRO-1), a marker used to isolate multilineage progenitors from bone marrow. The cell surface profile did not change over time and was similar to that of bone marrow mesenchymal cells. ${ }^{32}$ To further investigate whether hPIDM cells have characteristics of progenitor/stem cells, expression of ATP-binding cassette subfamily G member 2 (ABCG2), human telomerase reverse transcriptase (hTERT) and stem cell marker genes like Bmi1, Rex-1, Sox-2 was evaluated by real-time PCR analysis. Bmi-1, Rex-1, Sox-2 and ABCG2, but not hTERT, were expressed in all cultures examined (data not shown).

Multilineage potential of hPIDM cells. Based on morphological aspect, immunostaining experiments, realtime PCR and FACS analyses, hPIDM cells appear to resemble human adult mesenchymal stem/progenitor cells. $^{32,33}$ We therefore decided to investigate whether these cells have the capacity to differentiate into mesenchymal lineages, like adipogenic, osteogenic and chondrogenic. Induction of adipogenic differentiation resulted in cell growth arrest and in an enlarged cell morphology, consistent with what observed on commitment of preadipocytes. The majority of the cells accumulated intracytoplasmic lipid droplets that stained positive for Oil red $\mathrm{O}$, a specific dye for triglycerides. In contrast, no lipid vacuoles were observed in cells cultured in control medium (Figure 5a). Induction of adipogenesis was confirmed by realtime PCR analysis that showed an induction of expression of human peroxisome proliferator-activated receptor $\gamma_{2}$ (PPAR $\gamma 2$ ) and adipocyte fatty acid-binding protein (aFABP) genes in differentiated cells, as shown in Figure $5 \mathrm{~b}$. Cells cultured in osteogenic differentiation medium exhibited a strong alkaline phosphatase (AP) activity compared with 

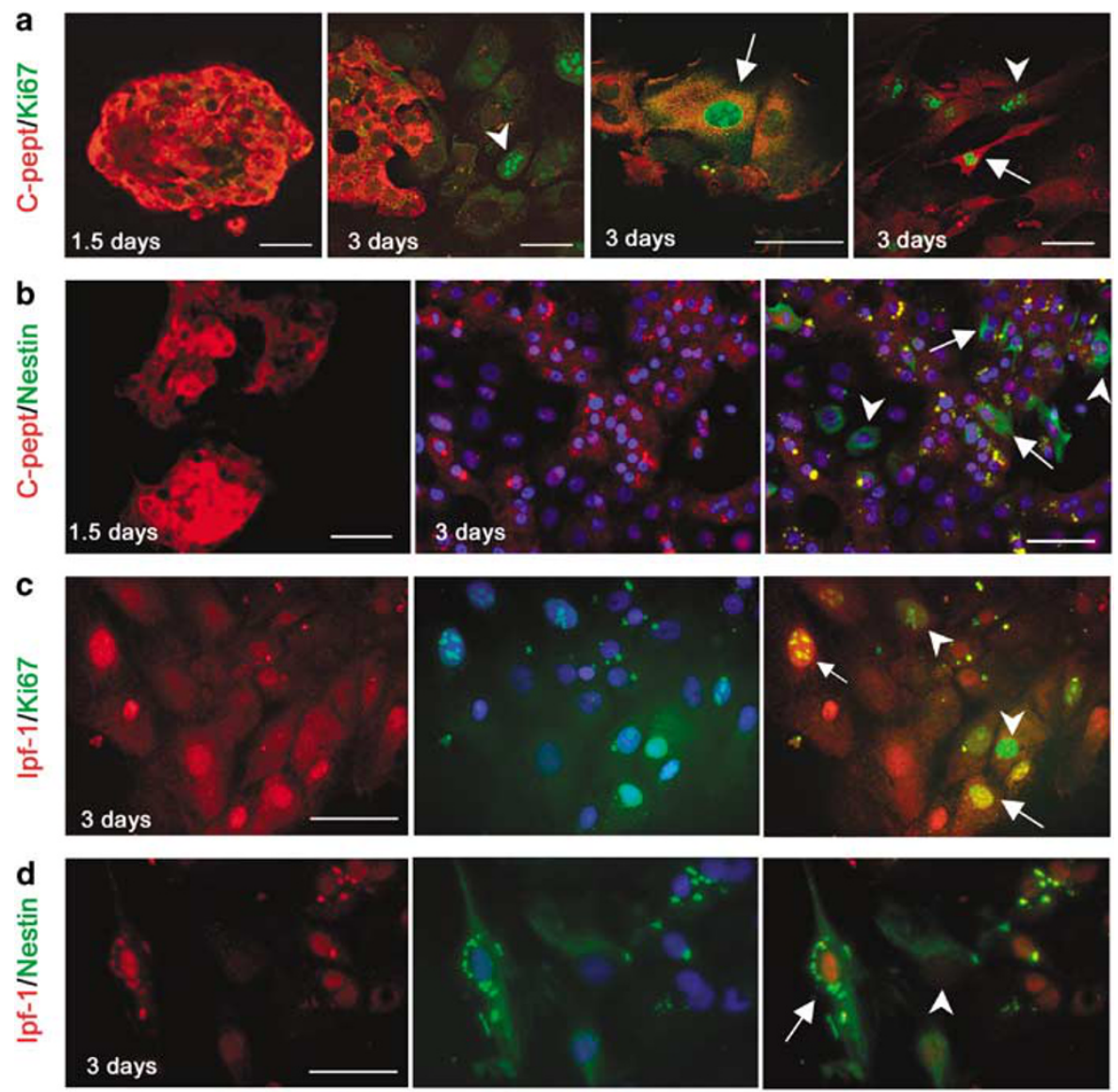

e

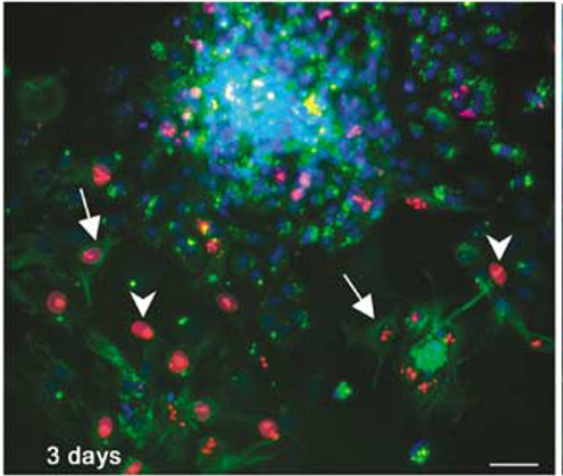

Ki67/Nestin

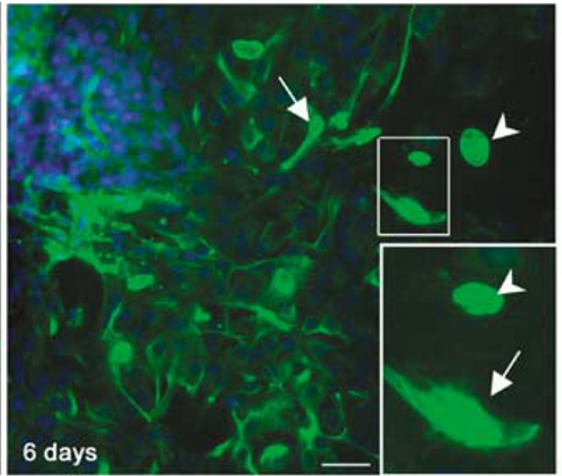

BrdU/Nestin

Figure 2 Characterization of cultured human pancreatic islets by immunofluorescence analysis. (a) Confocal images of staining for C-peptide (red) and Ki67 (green), at 1.5 and 3 days after islets plating. Arrows indicate proliferating C-peptide-positive cells; arrowheads show Ki67-positive/C-peptide-negative cells. (b) C-peptide (red) and nestin (green) expression in 1.5- and 3-day-old cultures. C-peptide-positive/nestin-positive and C-peptide-positive/nestin-negative are shown by arrows and arrowheads, respectively. (c and d) Three days islet-cultures stained for Ipf-1 (red) and Ki67 or nestin (green). The images display proliferating Ipf-1-expressing cells (arrows in c) and Ipf-1/ nestin double-positive cells (arrows in d). Arrowheads indicate proliferating and nestin-expressing cells that were negative for Ipf-1 (e, left panel). Cells coexpressing Ki67 (red) and nestin (green) are shown (arrows). Arrowheads indicate proliferating cells negative for nestin. (e, right panel) Double immunostaining using specific monoclonal antibodies anti-BrdU (green) and nestin (green) performed on 6-days islet cultures after $72 \mathrm{~h}$ of BrdU incorporation. Arrows and arrowheads indicate BrdU-positive/nestin-positive and BrdU-positive/nestin-negative cells, respectively. Although both antibodies were monoclonal and are revealed in green, expression of BrdU and nestin can be distinguished because of their respective nuclear and cytoplasmic localization, as showed in the enlargement. Nuclei are labeled in blue with Hoechst. Scale bar $=50 \mu \mathrm{m}$

control cells (Figure 5a). Moreover, accumulation of calcified extracellular matrix was observed following von Kossa staining (data not shown). To confirm osteogenic differentiation, expression of the lineage-specific genes core binding factor alpha 1 (CBFA-1) and AP was evaluated by real-time PCR. Expression of CBFA-1 was observed in cells induced to osteogenic differentiation. Consistent with AP staining, an increase of AP gene expression was observed in differentiated cells, although basal levels of expression were detected in non-induced cells 


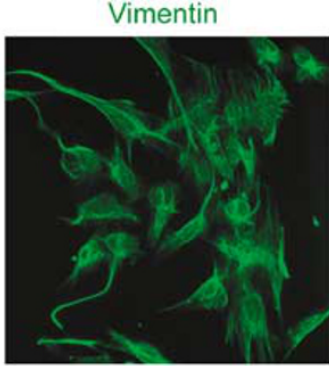

b

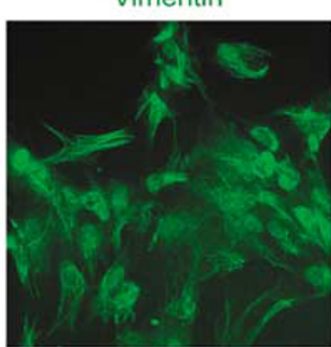

$\alpha \mathrm{SMA}$

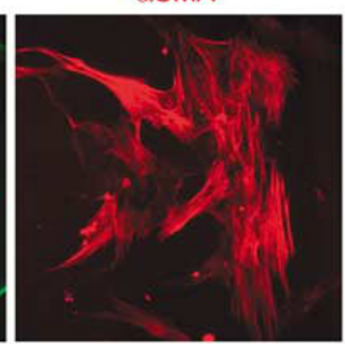

Nestin

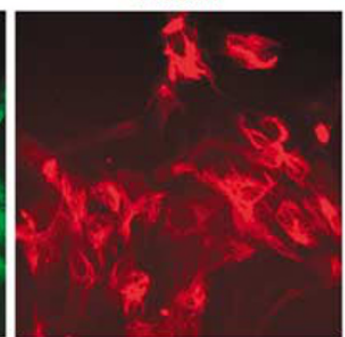

Vimentin/ $\alpha$ SMA/Hoechst

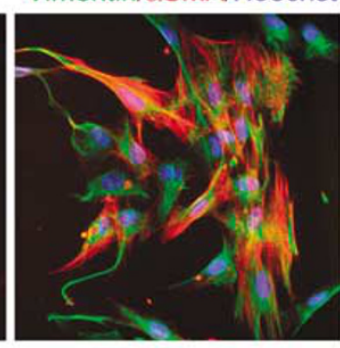

Vimentin/Nestin/Hoechst

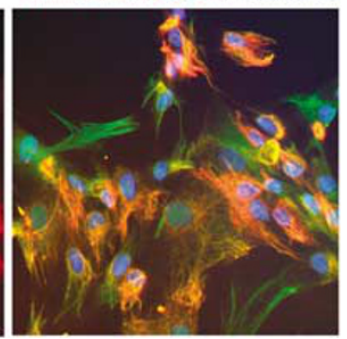

Figure 3 Expression of vimentin, $\alpha$-SMA and nestin in hPIDM cells. (a) Immunofluorescent labeling of vimentin (green) and $\alpha$-SMA (red) in cells at passage 2 revealed expression of both proteins in the majority of the cells. (b) Immunofluorescent labeling of vimentin (green) and nestin (red). Nuclei are stained in blue with Hoechst

(Figure 5b). Chondrogenic differentiation was performed according to the micromass technique as described previously. ${ }^{34}$ To assess chondrogenic differentiation, nodules were stained with Alcian Blue, a dye that binds to sulfated proteoglycans resulting in a blue color. Nodules induced to differentiate in chondrogenic medium stained more intensively compared with nodules that were maintained in control medium (Figure 5a), suggesting the presence of sulfated proteoglycans in the extracellular matrix. RT-PCR analysis revealed a significant increase of mRNA expression for the chondrogenic-specific protein Decorin in cells induced to chondrogenic differentiation compared with control cells (Figure 5b).

In vitro differentiation of hPIDM cells into insulinproducing ILCs. Fibroblast-like cells emerging from pancreatic islets have been shown to be able to differentiate into insulin-expressing cells. ${ }^{11-25}$ To evaluate the ability of hPIDM cells to differentiate into a pancreatic endocrine phenotype, cells were cultured for 21 days in a medium for endocrine differentiation. Under these conditions, cells formed clusters that remained adherent to culture plates for the first week, but afterward detached acquiring an isletlike morphology (Figure 6a). To determine whether the morphological differentiation into ILCs was accompanied by ultrastructural characteristics of $\beta$-cell differentiation, proliferating cells and differentiating clusters were analyzed by electron microscopy. In monolayer culture, several longshaped cells with ultrastructural features of fibroblasts were observed. These cells were characterized by a large nucleus containing a single large nucleolus. The cytoplasm contained few mitochondria, rough endoplasmic reticulum with dilated and parallel cisternae, some dense bodies and many glycogen granules (Figure 6b). Cells with a different level of differentiation characterized the multicellular ILCs. At the periphery of these clusters, a multilayer ring of fibroblasts was detected. These cells were similar to those in monolayer culture. Inside the ILCs, cells were round-shaped with a large irregular nucleus, a well-developed Golgi apparatus and abundant rough endoplasmic reticulum. In approximately $10 \%$ of these cells, organelles with ultrastructural features resembling those of $\beta$-cell granules were present (Figure 6b). We next tested whether, in accordance with morphological changes, the in vitro differentiation resulted in induction of insulin synthesis. Accordingly, semiquantitative RT-PCR analysis for insulin mRNA expression performed respectively after 7, 14 and 21 days of culture in differentiation conditions established a progressive activation of insulin gene expression (Figure 6c) compared to uninduced cells. In addition, a significant induction of expression of genes encoding insulin, glucagon, somatostatin, Ipf-1, NEUROD1, neurogenin-3, ISL-1, NKX2-2, NKX6-1, synaptophysin, PC1 and PC3, was observed by quantitative real-time PCR analysis (Figure $6 \mathrm{~d}$ ), further confirming the acquisition of a pancreatic endocrine phenotype by these ILCs. Expression levels of insulin, glucagon and somatostatin compared to normal human islets was: $0.56 \pm$ $0.29 \%$ for insulin, $0.17 \pm 0.11 \%$ for glucagon and $0.11 \pm 0.12 \%$ for somatostatin, calculated in a series of differentiation experiments performed in five different multi-organ donors, which showed similar results. Statistical analysis showed a significant upregulation of insulin $(P=0.009)$, glucagon $(P=$ $0.021)$, somatostatin $(P=0.02)$ and ISL-1 $(P=0.004)$ by Mann-Whitney test. Of note, this induction was accompanied by a significant downregulation of mesenchymal gene markers such as $\alpha$-SMA and vimentin.

In addition to the analysis of mRNA expression levels, the differentiation of hPIDM cells to an endocrine phenotype was verified by immunostaining for C-peptide, glucagon, somatostatin, Ipf-1 and Isl-1. In parallel, the same antibodies were used on HaCaT cells (a keratinocyte cell line used as a negative control) and on freshly isolated, noncultured human islet cells (used as positive control). As shown in Figure 7, all 
a

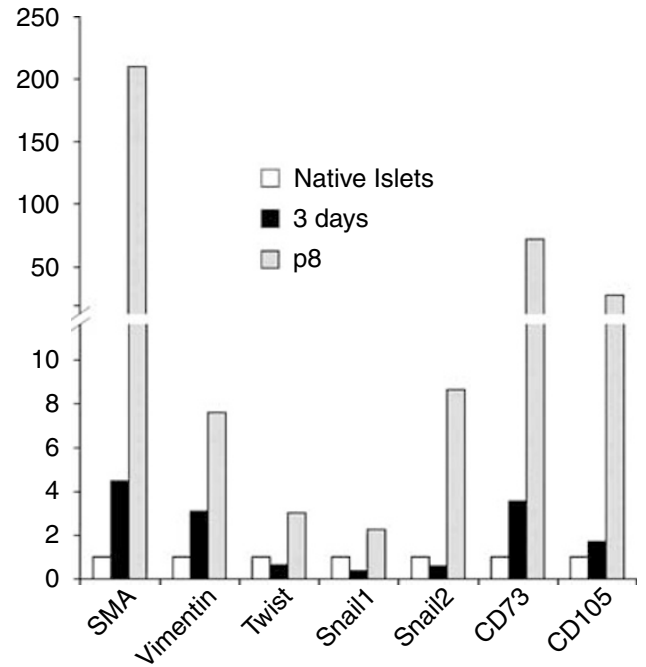

b
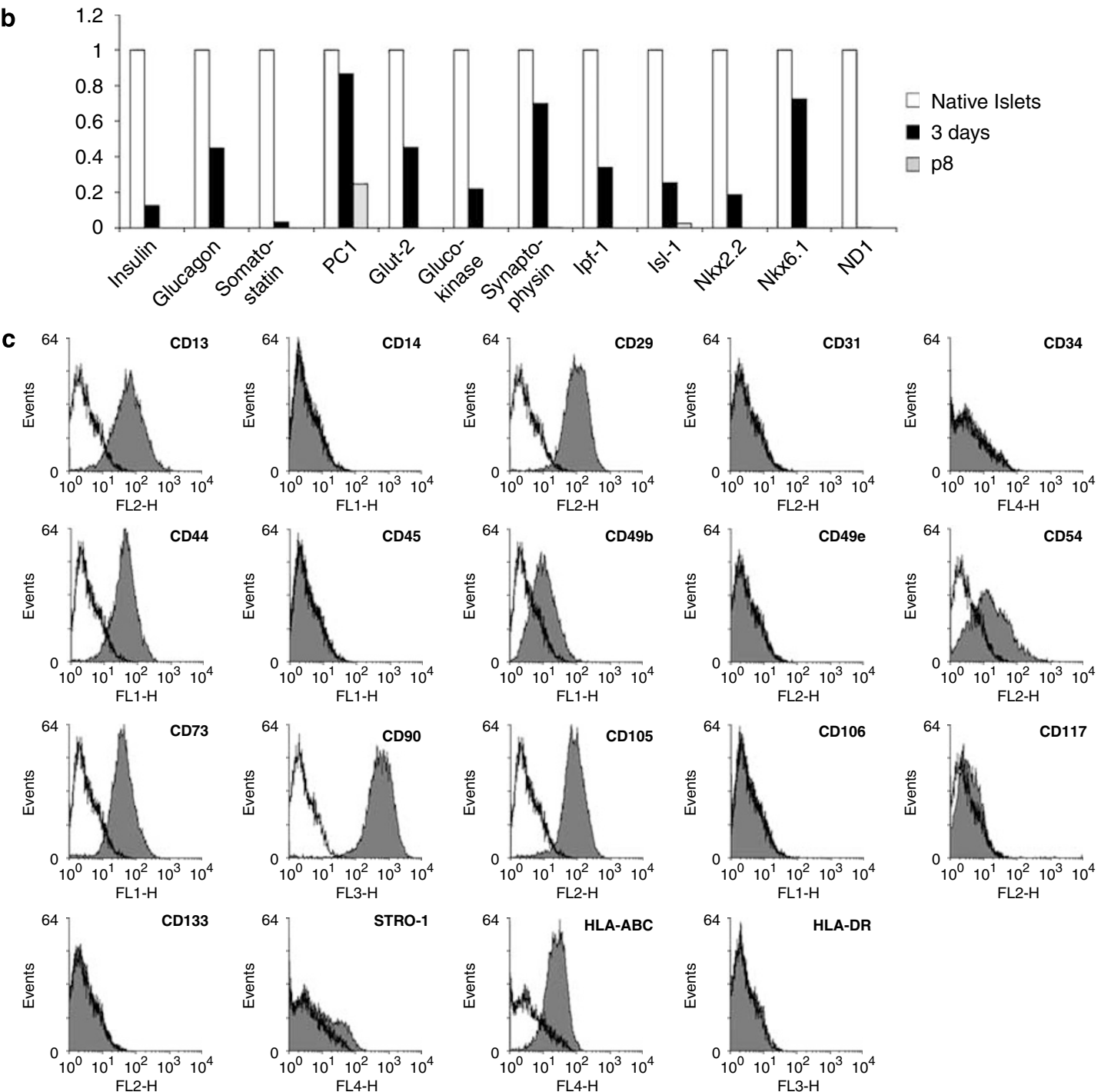

Figure 4 Characterization of hPIDM cells. Real-time quantitative PCR for the expression of mesenchymal (a) and pancreatic endocrine (b) genes from 3-day-old islet cultures and proliferating cells at passage 8 (p8). Data are reported as relative expression determined by normalizing expression of each target to endogenous controls (GAPDH, $\beta$ actin and HPRT) and then comparing this normalized value to the normalized expression in a reference sample (native islets). (c) Representative flow cytometry analysis of cell surface antigens of cultured cells (p8). Plots show specific antibody staining (filled) versus isotype control lgG staining (empty) 
Table 1 Surface antigen profile of hPIDM cells at different passages: early (p8), intermediate (p12) and late passages (p18)

\begin{tabular}{lrrr}
\hline Antigen & \multicolumn{1}{c}{$\mathbf{P 8}$} & \multicolumn{1}{c}{$\mathbf{P 1 2}$} & \multicolumn{1}{c}{$\mathbf{P 1 8}$} \\
\hline CD13 & $92.8 \pm 0.7$ & $95.4 \pm 3.2$ & $93.3 \pm 5.3$ \\
CD14 & $2.2 \pm 0.1$ & $2.1 \pm 0.2$ & $2.0 \pm 0.0$ \\
CD29 & $98.6 \pm 0.2$ & $97.6 \pm 2.2$ & $95.7 \pm 2.6$ \\
CD31 & $3.2 \pm 1.9$ & $2.0 \pm 0.0$ & $2.0 \pm 0.2$ \\
CD34 & $3.4 \pm 1.9$ & $3.9 \pm 0.5$ & $8.6 \pm 3.0$ \\
CD44 & $78.0 \pm 14.5$ & $95.4 \pm 3.8$ & $84.5 \pm 6.2$ \\
CD45 & $1.2 \pm 0.7$ & $2.1 \pm 0.2$ & $1.7 \pm 1.2$ \\
CD49b & $56.5 \pm 2.2$ & $65.0 \pm 2.0$ & $17.7 \pm 4.7$ \\
CD49e & $94.3 \pm 2.3$ & $93.7 \pm 5.5$ & $66.5 \pm 1.5$ \\
CD54 & $52.6 \pm 2.4$ & $64.1 \pm 2.4$ & $49.5 \pm 2.5$ \\
CD73 & $87.3 \pm 3.0$ & $94.5 \pm 3.0$ & $79.6 \pm 0.2$ \\
CD90 & $94.4 \pm 0.4$ & $98.3 \pm 1.5$ & $84.8 \pm 1.4$ \\
CD105 & $93.9 \pm 5.8$ & $97.9 \pm 1.7$ & $91.1 \pm 8.3$ \\
CD106 & $2.1 \pm 0.1$ & $1.8 \pm 0.0$ & $1.9 \pm 0.1$ \\
CD117 & $4.7 \pm 2.5$ & $3.2 \pm 0.2$ & $5.4 \pm 1.4$ \\
CD133 & $5.7 \pm 2.4$ & $2.0 \pm 0.1$ & $2.1 \pm 0.1$ \\
HLA-ABC & $63.1 \pm 3.7$ & $76.1 \pm 1.7$ & $71.7 \pm 6.5$ \\
HLA-DR & $1.9 \pm 0.1$ & $2.1 \pm 0.1$ & $2.3 \pm 0.4$ \\
STRO-1 & $2.9 \pm 0.9$ & $8.4 \pm 0.9$ & $6.4 \pm 3.6$ \\
\hline
\end{tabular}

Data are presented as the mean of percentages of positive cells \pm S.E.

a
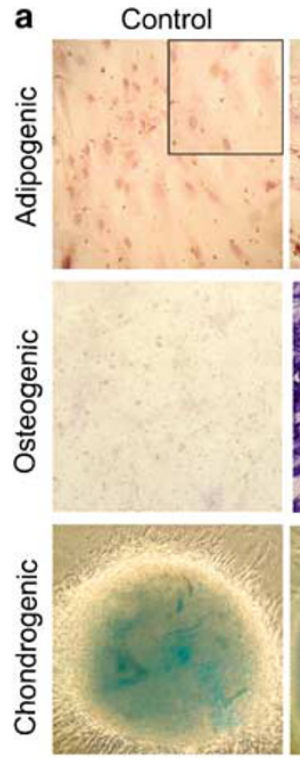

Figure 5 Differentiation of hPIDM cells into adipocytes, osteoblasts and chondrocytes. (a) hPIDM cells were cultured in adipogenic, osteogenic or chondrogenic medium. Intracellular lipid droplets are stained orange with Oil Red $O$ (induced). Osteoblastic differentiation was demonstrated by staining for AP. A stronger AP enzyme activity (purple) can be observed in osteo-induced cells compared to control cells after 3 weeks of induction. Cells formed nodules that stained positively for Alcian Blue, indicating pericellular proteoglycans deposition. A more intense staining can be observed in induced compared to non-induced cells. (b) Differentiation was confirmed by analysis of the expression of adipogenic-, osteogenic- and chondrogenic-specific genes by RT-PCR

antibodies gave a positive signal on human pancreatic islet cells and did not stain HaCaT cells. When tested on undifferentiated hPIDM cells, no specific signal was detected for C-peptide, glucagon, somatostatin and Ipf-1. In contrast, Isl-1 was the only antibody that consistently stained undiffer- entiated hPIDM cells. All antibodies, except that against Ipf-1, stained differentiated hPIDM cells, confirming that these cells have, at least partially, acquired an endocrine phenotype. Finally, we performed in vitro insulin secretion studies to determine whether these ILCs were able to secrete insulin. Insulin release was $13.2 \pm 10.2$ and $8.8 \pm 4.8 \mu \mathrm{U} / \mathrm{ml}$ at 3.3 and $16.7 \mathrm{mmol} / \mathrm{l}$ glucose, respectively, suggesting that such aggregates were indeed able to secrete insulin, although in a glucose-independent manner.

\section{Discussion}

Studies of the past years have demonstrated a variable ability of cells derived from different sources, including fetal and adult pancreas, to differentiate into insulin-expressing cells. Nevertheless, the nature and the characteristics of the various types of cells used are still controversial. High expectations have been recently raised by experimental evidence that cells with a mesenchymal morphology can be obtained from cultures of human pancreatic islet cells. On the basis of these results, it was initially proposed that these mesenchymal cells originated from $\beta$-cells undergoing an epithelial to mesenchymal transition. ${ }^{25}$ This transition would allow the expansion of the cells in the presence of serum whereas, following serum removal, the cells could regain an endocrine phenotype with synthesis and release of insulin. ${ }^{24,25,35}$ Mesenchymal stem cells capable to differentiating not only into osteocytes, adipocytes and chondrocytes, but also into insulin-expressing cells have been isolated from cultures of human pancreatic ductal epithelial cells. ${ }^{26}$ Immortalized mesenchymal cells derived from human pancreatic islets were reported not only to differentiate into hepatocytes and different mesenchymal cell lineages, but also to form insulin-expressing cells. ${ }^{12}$ In contrast, very recent reports from several laboratories have reported on studies based on genetic lineage tracing in mice that seem to rule out the possibility that $\beta$-cells could undergo an epithelial to mesenchymal transition, thus suggesting that the cell population obtained from cultures of pancreatic islets may originate from preexisting mesenchymal cells. ${ }^{27-30}$ Similar conclusions were obtained in experiments performed with transgenic mice expressing the green fluorescent protein (GFP) selectively in $\beta$-cells. In these experiments, although a conversion of GFP-expressing $\beta$-cells from an epithelial toward a mesenchymal morphology was observed in the early days of culture, GFP-expression was not observed in the expanded mesenchymal cell population, thus suggesting that GFP-expressing $\beta$-cells had been lost on further culture. ${ }^{30}$

To characterize the phenotype of proliferating-islet-derived cells in the initial days of culture, we analyzed the expression of nestin, an intermediate filament present in several undifferentiated precursor cells that has been found to be expressed in cultured islet cells under different conditions. ${ }^{10-12}$ Nestin expression has been reported to precede the appearance of $\beta$-cells during embryogenesis ${ }^{13}$ and to represent a possible marker of adult $\beta$-cell precursors. ${ }^{11,36}$ In our study, we observed that hPIDM cells appear to emerge from a mixed cell population. We did not detect nestin-positive cells in the first $36 \mathrm{~h}$ of culture; however, nestin-positive cells were easily observed in 3-day-old islet cultures and their number increased in the following days of culture. The 
a

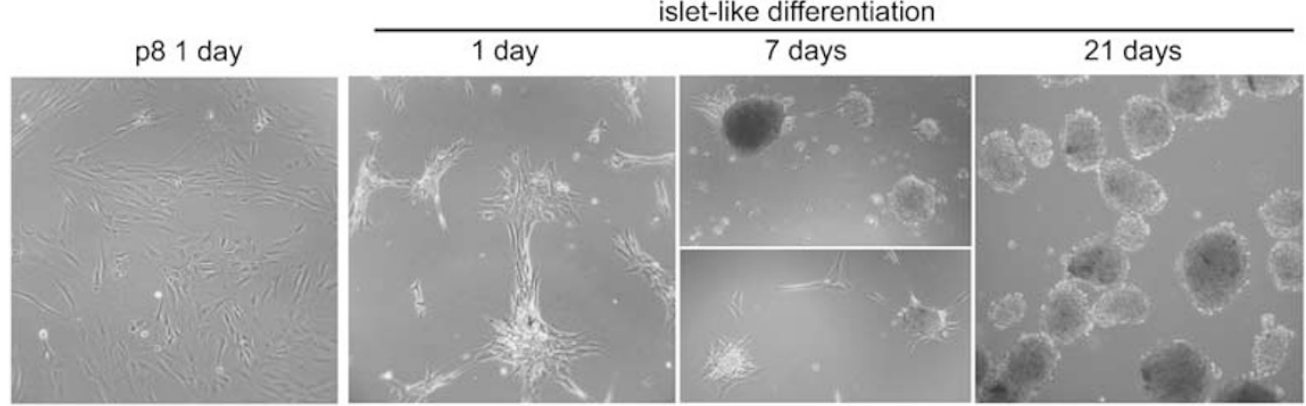

b

Ctrl

Ind

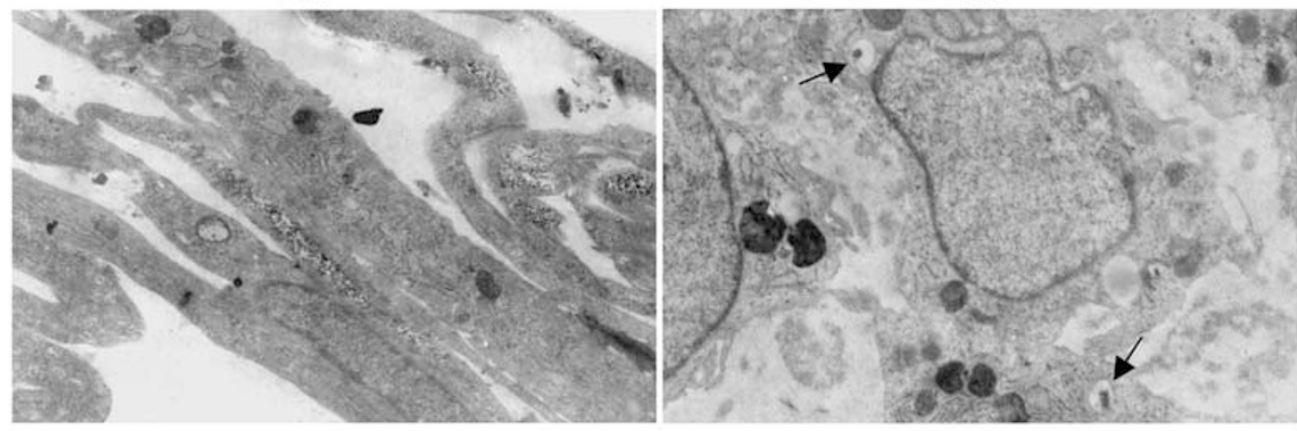

C

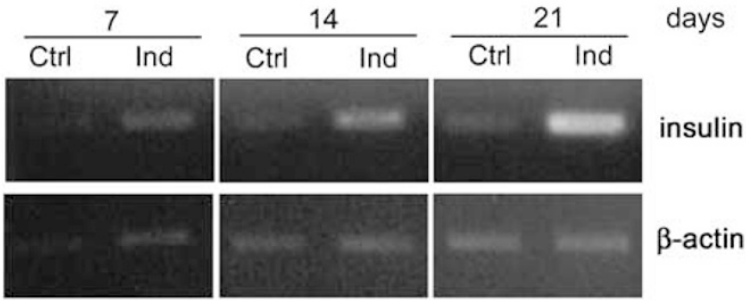

d

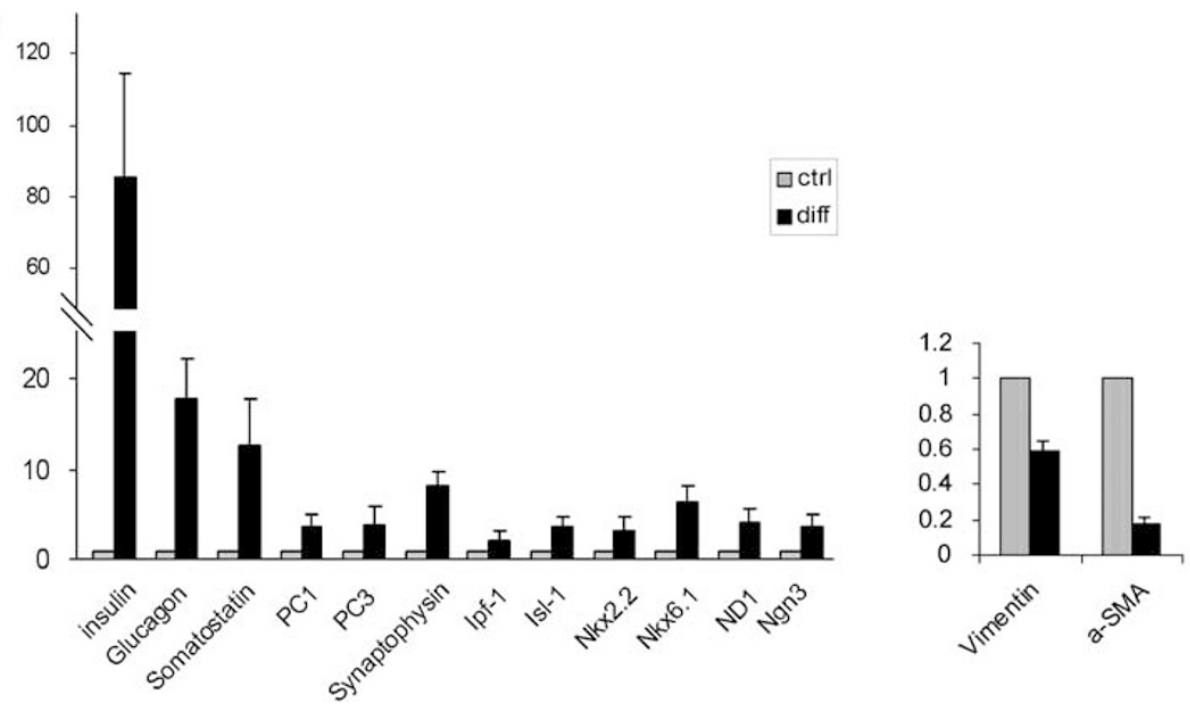

Figure 6 hPIDM cells differentiate into ILCs and show pancreatic endocrine phenotype. (a) Phase-contrast images of ILCs at different time in differentiation medium. (b) Electron microscopy images of a control cell with a typical fibroblast-phenotype (ctrl, magnification $\times 7000$ ) and of a cell after 21 days in differentiation medium (ind, magnification $\times 16000$ ). Structures similar to $\beta$ granules were observed in the cytoplasm of differentiated cells (arrows). (c) Semiquantitative RT-PCR analysis of Insulin mRNA performed on extracts from proliferating control cells (ctrl) and from cells after 7, 14, 21 days in differentiation medium (ind). (d) Real-time quantitative PCR, showing modulation of mRNA expression of the indicated neuroendocrine and mesenchymal genes in 21 days-induced cells compared with proliferating control cells. Results are expressed in arbitrary units after relative quantification against endogenous controls ( $\beta$-actin, GAPDH, HPRT) 

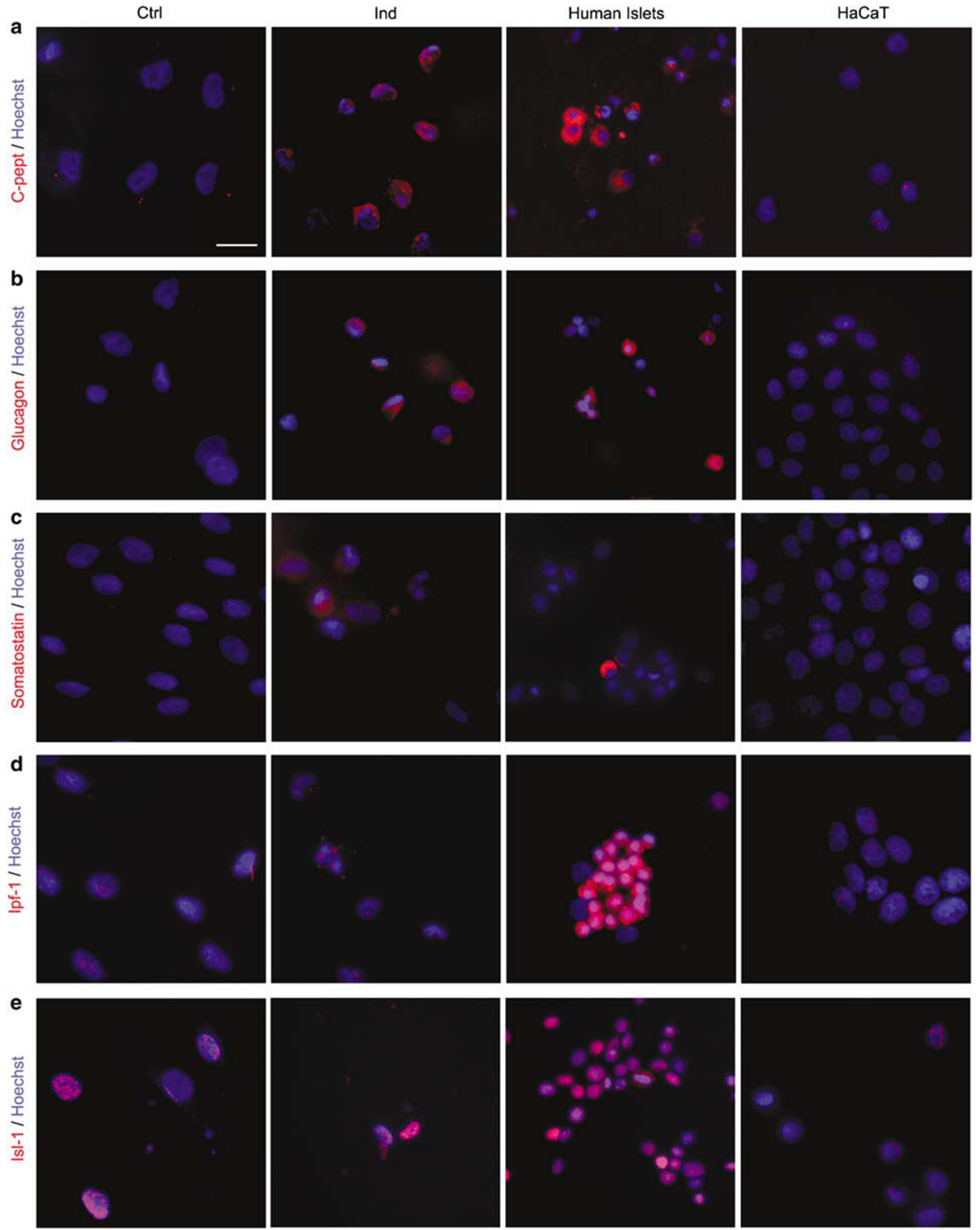

Figure 7 Immunocytochemistry for pancreatic endocrine markers in undifferentiated and differentiated hPIDM cells. Proliferating (Ctr) and differentiated (Ind) hPIDM cells were stained for C-peptide (a), glucagon (b), somatostatin (c), Ipf-1(d) and Isl-1 (e) (red). Human pancreatic islet and HaCaT cells were used as positive and negative control, respectively. Nuclei were labeled with Hoechst (blue). Scale bar $=20 \mu \mathrm{m}$ 
nestin-positive cell population included cells that stained either positive or negative for C-peptide. Similarly, a fraction of nestin-positive cells was also positive for Ipf-1. Nestin-positive cells were also labeled by Ki67 and by antibody against BrdU. Furthermore, a fraction of the cells expressing Ipf-1 were replicating, as shown by positivity for Ki67. However, after the first week in culture, almost all cells were positive for nestin, $\alpha$-SMA and vimentin, but resulted negative for $C$-peptide and Ipf-1. If cultured in the presence of FBS, hPIDM cells maintained a mesenchymal phenotype and could be induced to differentiate into chondrocytes, osteocytes and adipocytes, revealing multipotent differentiative properties similar to those reported for mesenchymal stem/precursor cells. ${ }^{32}$

The appearance in islet cell cultures of cells positive for both nestin and C-peptide or for both nestin and Ipf-1 would argue in favor of a conversion of $\beta$-cells from an epithelial to a mesenchymal phenotype. Similarly, positivity for Ki67 of cells expressing Ipf-1 would suggest that cells of epithelial origin can proliferate at least for a given time, as proposed initially by Hayek and co-workers. ${ }^{31}$ These authors have recently compared their protocol $^{4}$ with that of Gershengorn et al. ${ }^{25}$ confirming that, although with some differences in terms of number of cells and replication time, which may depend on the culture conditions used, initial proliferation of cells positive for Ipf-1 can be reproducibly observed at early stages of islet culture. However, taking into account the recent results from $\beta$-cell lineage tracing experiments, an alternative explanation of our findings is that even if there was an initial transition of $\beta$-cells to a mesenchymal phenotype at early times in culture, these cells may die off and be taken over by a population of mesenchymal cells that continue to proliferate and to persist at the later passages of these cultures, as observed in $\beta$-cells expressing GFP in mice. ${ }^{28}$

As it concerns the ability of hPIDM to acquire an endocrine phenotype, we observed that these cells were able, following appropriate stimulation, to form ILCs that expressed insulin and other endocrine markers and in parallel to downregulate the expression of mesenchymal genes. Accordingly, differentiated hPIDM cells resulted positive for C-peptide, glucagon, somatostatin and IsI-1, and were able to secrete insulin, although in a glucose-independent manner, likely because of the lack of GLUT-2 and glucokinase expression. Insulin expression by mesenchymal stem cells from tissues other than pancreas has been reported by some groups, ${ }^{20,23}$ but not by others. ${ }^{22}$ In contrast with the results obtained with hPIDM cells, we did not observe insulin expression in mesenchymal stem/precursor cells derived from other tissues, under conditions where hPIDM cells did (data not shown). These results would suggest that functional differences between mesenchymal stem/precursor cells from pancreatic tissue and those from other tissues may exist, whereby hPIDM cells, as a consequence of their pancreatic origin, may remain committed to a pancreatic endocrine phenotype. Indeed, gene expression analysis revealed that, in addition to insulin, the expression of some transcription factors expressed in endocrine pancreatic cells (including NKX2-2 and NKX6-1) were expressed in hPIDM cells, but not in mesenchymal precursor/ stem cells derived from other tissues (data not shown).

In conclusion, we propose that hPIDM cells may represent a good substrate for developing an alternative source of insulin- producing cells for transplantation in humans. However, additional studies are necessary to optimize protocols for endocrine differentiation and to molecularly engineer these cells to improve insulin production and to restore glucosedependent insulin secretion.

\section{Materials and Methods}

Isolation of human pancreatic islets. Human pancreatic islets were obtained from five nondiabetic multi-organ donors (aged 43.2 \pm 19.4 years; gender: $3 \mathrm{M} / 2 \mathrm{~F}$; body mass index: $24.9 \pm 1.3 \mathrm{~kg} / \mathrm{m}^{2}$ ). Purified islets were prepared by intraductal collagenase solution injection and density gradient purification. ${ }^{37}$ At the end of the isolation procedure, islets were resuspended in M199 culture medium (supplemented with $10 \%$ serum and antibiotics) and cultured at $27^{\circ} \mathrm{C}$ in a $\mathrm{CO}_{2}$ incubator.

Cell culture. Approximately 50 islet equivalents, without dissociation, were cultured in $100 \mathrm{~mm}$ plastic tissue culture dishes (Falcon; Becton Dickinson, San Jose, CA, USA) in growth medium (GM) (modified RPMl 1640 medium (11.1 mM glucose) (Sigma Aldrich, St. Louis, Mo, USA) supplemented with 10\% FBS (Stem Cell Technologies Inc., Vancouver, BC, Canada), $2 \mathrm{mM}$ L-glutamine, $100 \mathrm{U} / \mathrm{ml}$ penicillin, $100 \mu \mathrm{g} / \mathrm{ml}$ streptomycin, $250 \mathrm{ng} / \mathrm{ml}$ amphotericin B, (Sigma)) and maintained at $37^{\circ} \mathrm{C}$ in $5 \% \mathrm{CO}_{2}$ and $95 \%$ humidified air. After 15 days of culture, adherent islets were detached with $0.25 \%$ trypsin-2 mM EDTA (Sigma) and seeded at a density of 12000 cells $/ \mathrm{cm}^{2}$ for two passages and subsequently at a density of $4000 \mathrm{cells} / \mathrm{cm}^{2}$. Culture medium was replaced every 3 days. HaCaT cells were cultured in Dulbecco's modified eagle's medium supplemented with $10 \%$ of FBS.

Immunofluorescence. Immunofluorescence for C-peptide, glucagon, somatostatin, Ipf-1, Isl-1, Ki67, vimentin, $\alpha$-SMA, nestin was performed on human islets, hPDMl and $\mathrm{HaCat}$ (used as negative control) grown directly on $12 \mathrm{~mm}$ glass slides. For native human islets (used as positive control) and for differentiated ILCs, immunofluorescence was performed after trypsin dissociation into single cells followed by centrifugation on microscope slides for $10 \mathrm{~min}$ at 1000 r.p.m. Cells were fixed with $4 \%$ paraformaldehyde in PBS for $20 \mathrm{~min}$ at room temperature (RT) and then permeabilized with $0.25 \%$ Triton X-100 for 10 min at RT, except for anti-Cpeptide and anti Isl-1staining, where cells were permeabilized with 50 and $100 \%$ Methanol, respectively, for $20 \mathrm{~min}$ at $-20^{\circ} \mathrm{C}$ and then incubated for $45 \mathrm{~min}$ at RT with blocking solution ( $1 \%$ bovine serum albumin (BSA), 10\% FBS in PBS). For Ipf-1 staining, the cells, after fixation, were incubated for $30 \mathrm{~min}$ with permeabilizingblocking buffer (PBS $50 \mathrm{mM}$ glycine, $0.1 \%$ Triton X-100, 2\% BSA, 2\% normal goat serum (NGS)). All primary antibodies were diluted in PBS containing $1 \%$ BSA or in blocking solution for Isl-1 or in 5\% NGS for Ipf-1 staining. Rabbit anti-human Cpeptide (Linco Research Inc., St. Charles, MO, USA; diluted 1:1000) and rabbit anti-PDX-1(Ipf-1) (Chemicon, Temecula, CA, USA; AB3503, diluted 1:2000) were incubated overnight at $4^{\circ} \mathrm{C}$; mouse anti Isl-1 (Developmental Studies Hybridoma Bank, lowa, IA, USA; 39.4D5, diluted 1:600); rabbit anti-human glucagon and somatostatin (Dako Corporation, Carpinteria, CA, USA; diluted 1:1000); mouse anti- $\alpha$-SMA (Sigma; clone 1A4, diluted 1:400); mouse anti-human nestin (Chemicon, Temecula, CA, USA; MAB 5326, diluted 1:200); rabbit monoclonal anti Ki67 (clone SP6, Lab Vision Corporation, Fremont, CA, USA; diluited 1:200) were incubated for $2 \mathrm{~h}$ at RT; rabbit anti-human vimentin (Abcam plc, Cambridge, UK; diluted 1:150) was incubated for $30 \mathrm{~min}$ at $37^{\circ} \mathrm{C}$. For double immunofluorescence with Ipf-1, rabbit anti Ki67 antibody was labeled with Alexa Fluor 488 Monoclonal Antibody Labeling Kit (Molecular Probes, Leiden, NL, USA) according to the manufacturer's instructions. Negative controls were performed omitting primary antibodies. After incubation with primary antibodies, cells were washed with PBS and then incubated with Alexa Fluor 488 (Molecular Probes) or Cy5 conjugated (Jacksons ImmunoResearch Laboratories) goat anti-rabbit IgG, or with TRITC (Sigma) or Cy3-conjugated (Jacksons ImmunoResearch Laboratories) goat-anti mouse IgG (Sigma). After nuclear staining with Hoechst 33258, slides were mounted with Vectashield (Vector, Burlingame, CA, USA) and analyzed with an Olympus IX microscope or with a LSM 510-Meta Zeiss confocal microscope.

Cell proliferation assay. Cell proliferation was evaluated by BrdU labeling with detection kit I (Roche Diagnostic $\mathrm{GmbH}$ ). BrdU was added to the medium at $10 \mu \mathrm{M}$ for $72 \mathrm{~h}$ and double immunofluorescence for anti-nestin and anti-BrdU was performed as described previously. ${ }^{38}$ 
Flow cytometry. Immunophenotypic analysis was performed on cells from early (P8), middle (P12) and late (P18) passages. Subconfluent cells were detached with $0.25 \%$ trypsin-2 mM EDTA and washed with ice-cold PBS/2 mM EDTA/0.5\% BSA buffer. A $1 \times 10^{5}$ portion of cells were labeled with the following monoclonal antibodies: CD14-FITC (clone M5E2), CD29-PE (clone MAR4), CD34-APC (clone 581), CD49b-FITC (clone AK-7), CD49e-PE (clone IIA1), CD54-PE (clone HA58), purified CD73 (clone MOPC-21), CD90-PeCY5 (clone 5E10), CD117-PE (clone YB5.B8), HLA-ABC-APC (clone G46-2.6), HLA-DR-PeCY5 (clone G46-6), all from BD Pharmingen (Franklin Lakes, NJ, USA), CD13-PE (clone WM47), CD44-FITC (clone DF1485), all from DAKO Corporation (Carpinteria, CA, USA), CD31-PE (clone 10G9), CD45-FITC (clone 35-Z6), both from Santa Cruz Biotechnology (Santa Cruz, CA, USA), CD105-PE (clone SN6; Ancell, Bayport, MN, USA), CD133PE (clone A1; Miltenyi Biotec, Sunnyvale, CA, USA) and purified STRO-1 (clone stro-1; R\&D system, Minneapolis, MN, USA). Rat anti-mouse $\lg _{1}$ (clone A85-1; $\mathrm{BD}$ ) and rat anti-mouse IgM (clone II41-1; BD) were used as secondary antibodies. Goat anti-mouse $\lg _{1}$ (clone MOPC-21; BD) was used as isotype control. Cells were stained in ice-cold PBS/2 mM EDTA $/ 0.5 \%$ BSA buffer, for $30 \mathrm{~min}$, at $4^{\circ} \mathrm{C}$. Primary antibodies were further incubated with respective secondary antibodies for 30 min at $4^{\circ} \mathrm{C}$. After the final wash, cells were fixed in $1 \%$ paraformaldehyde before FACS analysis. A total of 10000 events were acquired and analyzed using FACS Calibur-flow cytometry system running CellQuest software (BD).

\section{Induction of adipogenic, osteogenic and chondrogenic} differentiation. hPIDM cells were induced to differentiate toward the adipogenic, osteogenic and chondrogenic lineages, as described previously. ${ }^{32}$ For adipogenic differentiation, cells were plated at a density of $20000 \mathrm{cells} / \mathrm{cm}^{2}$ and cultured for 4 weeks in GM, containing $0.5 \mathrm{mM} \mathrm{IBMX}, 1 \mu \mathrm{M}$ dexamethasone, $10 \mu \mathrm{M}$ insulin, $200 \mu \mathrm{M}$ indometacin (all from Sigma). The differentiation medium was replaced every 2-3 days. Cells maintained in GM were used as controls. Adipogenesis was assessed using Oil Red $O$ staining as an indicator of intracellular lipid accumulation. Cells were washed twice with PBS and fixed for 60 min at RT with $4 \%$ formaldehyde $/ 1 \% \mathrm{CaCl}_{2}$. After washing with $70 \%$ ethanol, the cells were incubated for $10 \mathrm{~min}$ at RT in $2 \%$ Oil Red $\mathrm{O}$ reagent (Sigma). Finally, they were rinsed once with $70 \%$ ethanol and twice with $\mathrm{dH}_{2} \mathrm{O}$ and counterstained with hematoxylin (Sigma) for $10 \mathrm{~min}$. Osteogenesis was induced by culturing the cells for 3 weeks in GM, supplemented with $0.1 \mu \mathrm{M}$ dexamethasone, $50 \mu \mathrm{M}$ ascorbate-2phosphate, $10 \mathrm{mM} \beta$-glycerophosphate (all from Sigma). The medium was replaced every 2-3 days and differentiation assessed by detecting AP activity and by Von Kossa staining. To detect AP activity, cells were washed twice with PBS, then incubated for $40 \mathrm{~min}$ in $1 \%$ AP solution $(0.25 \%$ naphtol phosphate, $1 \mathrm{mg} / \mathrm{ml}$ Fast blue RR; Sigma) at $37^{\circ} \mathrm{C}$ and washed with PBS. For Von Kossa staining, the cells were cultured for 4 weeks in the differentiation medium then fixed in $4 \%$ paraformaldehyde for 60 min at RT, rinsed with $\mathrm{dH}_{2} \mathrm{O}$ and incubated in the dark for 30 min with $1 \%$ silver nitrate (Sigma). Finally, cells were washed with $\mathrm{dH}_{2} \mathrm{O}$ and developed under UV light for $60 \mathrm{~min}$. For chondrogenic differentiation, cells were cultured in a micromass culture. ${ }^{34}$ Briefly, $10 \mu \mathrm{l}$ of a concentrated cell suspension $\left(8 \times 10^{6} \mathrm{cells} / \mathrm{ml}\right)$ were placed into the center of a $35 \mathrm{~mm}$ tissue culture dish and allowed to attach at $37^{\circ} \mathrm{C}$ for $2 \mathrm{~h}$. Differentiation medium (RPMI $1640,2 \mathrm{mM}$ L-glutamine, $100 \mathrm{U} / \mathrm{ml}$ penicillin, $100 \mu \mathrm{g} / \mathrm{ml}$ streptomycin, $250 \mathrm{ng} / \mathrm{ml}$ amphotericin B (Sigma) containing 1\% FBS (Stem Cells Technologies Inc.), $6.25 \mu \mathrm{g} / \mathrm{ml}$ insulin, $50 \mathrm{nM}$ ascorbate-2-phosphate (both from Sigma) and $10 \mathrm{ng} / \mathrm{ml}$ TGF- $\beta 1$ (Celbio, Pero, Ml, Italy)) was gently added to the plate and the cells were maintained in culture for 3 weeks before analysis. Chondrogenesis was assessed by Alcian blue staining. Briefly, cells were fixed in $4 \%$ paraformaldehyde for $15 \mathrm{~min}$ at RT, washed twice with PBS and incubated for 30 min with $1 \%$ Alcian blue (Sigma) in $0.1 \mathrm{~N} \mathrm{HCl}$. Finally, cells were washed in $0.1 \mathrm{~N} \mathrm{HCl}$ for 5 min to remove excess stain.

Induction of pancreatic endocrine differentiation. To induce a pancreatic endocrine differentiation, 600000 cells were plated in six-well plastic dishes with differentiation medium consisting in RPMI 1640 supplemented with insulin $(10 \mu \mathrm{g} / \mathrm{ml})$, transferrin $(5.5 \mu \mathrm{g} / \mathrm{ml})$, sodium selenite $(6.7 \mathrm{ng} / \mathrm{ml})$ and $1 \%$ BSA (all from Sigma). Cells maintained in GM were used as controls. Culture medium was changed every 3 days.

Electron microscopy analysis. Cells were fixed in $2.5 \%$ glutaraldehyde in $0.1 \mathrm{M}$ phosphate buffer for 20 min at RT, washed in $0.1 \mathrm{M}$ phosphate buffer $(\mathrm{pH} 7.3)$, post-fixed in $0.1 \%$ osmium tetroxide in $0.1 \mathrm{M}$ phosphate buffer $(\mathrm{pH} 7.3$ ) and dehydrated in a graded series of ethanol. ILCs and monolayer cells, mechanically scraped in the last phase of dehydration, were centrifuged to obtain a pellet.
Centrifuged pellets were transferred to propylene oxide and embedded in PolyBed 812. Ultrathin sections were cut with a diamond knife, stained with uranyl acetate and lead citrate, and observed under a Zeiss 902 transmission electron microscope.

RNA preparation and real-time PCR. Total RNA was extracted using RNeasy Mini Kit (Qiagen, Valencia, CA, USA) and treated with DNase I using RNase-free DNase set (Qiagen) to eliminate genomic DNA. RNA $(0.5 \mu \mathrm{g})$ was reverse transcribed using $200 \mathrm{U}$ of Moloney murine leukemia virus reverse transcriptase (Promega, Madison, WI, USA), 2 mM dNTPs and $0.25 \mu$ g of oligo (dT) (Invitrogen, Carlsbad, CA, USA). RNasin (Promega) was added to the reaction mix to avoid RNA degradation. Aliquots of the total cDNA were amplified in $25 \mu \mathrm{l}$ of PCR reaction mixture containing $1 \times \mathrm{MgCl}_{2}$-free buffer, $1.5 \mathrm{mM} \mathrm{MgCl}_{2}$ (both from Roche Molecular System, NJ, USA), $0.2 \mathrm{mM}$ dNTPs mix (Promega), $10 \mathrm{pmol}$ of sense and antisense primers (Invitrogen) and $1.5 \mathrm{U} /$ reaction of AmpliTaq Gold Polymerase (Roche Molecular System). PCR conditions included an initial denaturation step of $10 \mathrm{~min}$ at $94^{\circ} \mathrm{C}$, followed by $30-40$ cycles of $1 \mathrm{~min}$ denaturation at $94^{\circ} \mathrm{C}, 1 \mathrm{~min}$ at annealing temperature and 1 min extension at $72^{\circ} \mathrm{C}$, with a final elongation step at $72^{\circ} \mathrm{C}$ for 5 min. Real-time PCR reactions were carried out using a Euroclone One Gradient PCR machine (Euroclone, Pero, MI, Italy). Amplified products were separated by electrophoresis on a $1.6-2 \%$ agarose gel (Roche-Boerhinger Mannheim $\mathrm{GmbH}$, Germany) and visualized by ethidium bromide staining.

The following primers and PCR conditions were used: aFABP (280 bp): sense, 5'-GCTTTGCCACCAGGAAAGTG-3'; antisense, 5'-ATGACGCATTCCACCACC AG-3' (30 cycles, annealing temperature: $59^{\circ} \mathrm{C}$ ); PPAR $\gamma 2$ (325 bp); sense, $5^{\prime}-\mathrm{GCT}$ GTTATGGGTGAAACTCTG-3'; antisense, 5'-ATAAGGTGGAGATGCAGGCTC-3' (40 cycles, annealing temperature: $59^{\circ} \mathrm{C}$ ); CBFA-1 (320 bp): sense, $5^{\prime}$-CTCACTA CCACACCTACCTG-3'; antisense, 5'-TCAATATGGTCGCCAAACAGATTC-3' (35 cycles, annealing temperature: $55^{\circ} \mathrm{C}$ ); AP (196 bp): sense, $5^{\prime}$-CCACGTCTTCAC

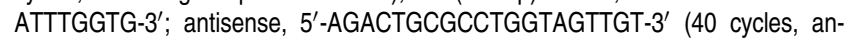
nealing temperature: $59^{\circ} \mathrm{C}$ ); decorin (300 bp): sense, $5^{\prime}$-CCTTTGGTGAAGTTG GAACG-3'; antisense, 5'-AAGATGTAATTCCGTAAGGG-3' (35 cycles, annealing temperature: $54^{\circ} \mathrm{C}$ ); insulin (261 bp): sense, $5^{\prime}$-GCCTTTGTGAACCAACACCTG-3'; antisense, $5^{\prime}$-GTTGCAGTAGTTCTCCAGCTG-3' (35 cycles, annealing temperature: $\left.60^{\circ} \mathrm{C}\right) ; \quad \beta$-actin $(377 \mathrm{bp})$ : sense, $5^{\prime}$-CAACTCCATCATGAAGTGTGAC-3'; antisense, $5^{\prime}$-GCCATGCCAATCTCATCTTG-3' (25 cycles, annealing temperature: $\left.58^{\circ} \mathrm{C}\right)$.

Real-time quantitative PCR. Quantitative analysis of human mRNA expression of the genes of interest was performed by real-time PCR using TaqMan $^{\mathrm{TM}}$ Pre-Developed Assay Reagents (Applied Biosystems, Foster City, CA, USA) and the ABI PRISM 7900HT Sequence Detection System (Applied Biosystems). Samples were run in triplicate and their relative expression was determined by normalizing expression of each target to endogenous controls and then comparing this normalized value to the normalized expression in a reference sample to calculate a fold-change value. All values were normalized with three endogenous controls, glyceraldehyde-3-phosphate dehydrogenase (GAPDH), $\beta$ actin and hypoxanthine guanine phosphoribosyl transferase (HPRT), which yielded similar results.

Insulin secretion. Insulin secretion in response to glucose was assessed in differentiated ILCs as described previously. ${ }^{39}$ Briefly, cells were kept at $37^{\circ} \mathrm{C}$ for $45 \mathrm{~min}$ in Krebs-Ringer bicarbonate solution (KRB), $0.5 \%$ albumin (pH 7.4), containing $3.3 \mathrm{mmol} / \mathrm{l}$ glucose. At the end of this period, medium was completely removed and replaced with $\mathrm{KRB}$ containing either $3.3 \mathrm{mmol} / \mathrm{l}$ glucose or $16.7 \mathrm{mmol} / \mathrm{l}$ glucose. After additional $45 \mathrm{~min}$ of incubation, the medium was removed. Samples $(500 \mu l)$ from the different media were stored at $-20^{\circ} \mathrm{C}$ prior measurement of insulin concentration by IRMA (Pantec Forniture Biomediche, Turin, Italy).

Acknowledgements. This work was supported by a core grant from Regione Toscana to the Center for Stem Cell Research, University of Siena, and by grants from the Italian Ministry of Health and from the Umberto Di Mario ONLUS Foundation.

1. Shapiro AM, Lakey JR, Ryan EA, Korbutt GS, Toth E, Warnock GL et al. Islet transplantation in seven patients with type 1 diabetes mellitus using a glucocorticoid-free immunosuppressive regimen. N Engl J Med 2000; 343: 230-238. 
2. Bonner-Weir S, Taneja M, Weir GC, Tatarkiewicz K, Song KH, Sharma A et al. In vitro cultivation of human islets from expanded ductal tissue. Proc Natl Acad Sci USA 2000; 97 7999-8004.

3. Abraham EJ, Leech CA, Lin JC, Zulewski H, Habener JF. Insulinotropic hormone glucagon-like peptide-1 differentiation of human pancreatic islet-derived progenitor cells into insulin-producing cells. Endocrinology 2002; 143: 3152-3161.

4. Beattie GM, Itkin-Ansari $P$, Cirulli V, Leibowitz G, Lopez AD, Bossie $S$ et al Sustained proliferation of PDX-1 cells derived from human islets. Diabetes 1999; 48 : 1013-1019.

5. Kodama S, Kuhtreiber W, Fujimura S, Dale EA, Faustman DL. Islet regeneration during the reversal of autoimmune diabetes in NOD mice. Science 2003; 302 1223-1227.

6. Dor Y, Brown J, Martinez OI, Melton DA. Adult pancreatic beta-cells are formed by selfduplication rather than stem-cell differentiation. Nature 2004; 429: 41-46.

7. Gao R, Ustinov J, Pulkkinen MA, Lundin K, Korsgren O, Otonkoski T. Characterization of endocrine progenitor cells and critical factors for their differentiation in human adult pancreatic cell culture. Diabetes 2003; 52: 2007-2015

8. Bodnar CA, Sen A, Kallos MS, Behie LA, Petropavlovskaia M, Rosenberg L. Characterization of human islet-like structures generated from pancreatic precursor cells in culture. Biotechnol Bioeng 2006; 93: 980-988.

9. Suzuki A, Nakauchi $H$, Taniguchi $H$. Prospective isolation of multipotent pancreatic progenitors using flow-cytometric cell sorting. Diabetes 2004; 53: 2143-2152.

10. Maria-Engler SS, Correa-Giannella ML, Labriola L, Krogh K, Colin C, Lojudice FH et al. Colocalization of nestin and insulin expression of islet cell markers in long-term human pancreatic nestin-positive cell cultures. J Endocrinol 2004; 183: 455-467.

11. Zulewski H, Abraham EJ, Gerlach MJ, Daniel PB, Moritz W, Muller B et al. Multipotentia nestin-positive stem cells isolated from adult pancreatic islets differentiate ex vivo into pancreatic endocrine, exocrine, and hepatic phenotypes. Diabetes 2001; 50: 521-533.

12. Eberhardt M, Salmon $P$, von Mach MA, Hengstler JG, Brulport M, Linscheid $P$ et al. Multipotential nestin and Isl-1 positive mesenchymal stem cells isolated from human pancreatic islets. Biochem Biophys Res Commun 2006; 345: 1167-1176.

13. Bernardo AS, Barrow J, Hay CW, McCreath K, Kind AJ, Schieke AE et al. Presence of endocrine and exocrine markers in EGFP-positive cells from the developing pancreas of nestin/EGFP mouse. Mol Cell Endocrinol 2006; 253: 14-21.

14. Treutelaar MK, Skidmore JM, Dias-Leme CL, Hara M, Zhang L, Simeone D et al. Nestinlineage cells contribute to the microvasculature but not endocrine cells of the islet. Diabetes 2003; 52: 2503-2512.

15. Zhang L, Hong TP, Hu J, Liu YN, Wu YH, Li LS. Nestin-positive progenitor cells isolated from human fetal pancreas have phenotypic markers identical to mesenchymal stem cells. World J Gastroenterol 2005; 11: 2906-2911.

16. Holland AM, Gonez LJ, Harrison LC. Progenitor cells in the adult pancreas. Diabetes Metab Res Rev 2004; 20: 13-27.

17. Lumelsky N, Blondel O, Laeng P, Velasco I, Ravin R, McKay R. Differentiation of embryonic stem cells to insulin-secreting structures similar to pancreatic islets. Science 2001; 292: 1389-1394.

18. D'Amour KA, Bang AG, Eliazer S, Kelly OG, Agulnick AD, Smart NG et al. Production of pancreatic hormone-expressing endocrine cells from human embryonic stem cells. Nat Biotechnol 2006; 24: 1392-1401.

19. Moriscot C, de Fraipont F, Richard MJ, Marchand M, Savatier P, Bosco D et al. Human bone marrow mesenchymal stem cells can express insulin and key transcription factors of the endocrine pancreas developmental pathway upon genetic and/or microenvironmental manipulation in vitro. Stem Cells 2005; 23: 594-603.

20. D'Ippolito G, Diabira S, Howard GA, Menei P, Roos BA, Schiller PC. Marrow-isolated adult multilineage inducible (MIAMI) cells, a unique population of postnatal young and old human cells with extensive expansion and differentiation potential. J Cell Sci 2004; 117: 2971-2981.
21. lanus A, Holz GG, Theise ND, Hussain MA. In vivo derivation of glucose-competent pancreatic endocrine cells from bone marrow without evidence of cell fusion. $J$ Clin Invest 2003; 111: 843-850.

22. Lechner A, Yang YG, Blacken RA, Wang L, Nolan AL, Habener JF. No evidence for significant transdifferentiation of bone marrow into pancreatic beta-cells in vivo. Diabetes 2004; 53: 616-623.

23. Timper K, Seboek D, Eberhardt M, Linscheid P, Christ-Crain M, Keller U et al. Human adipose tissue-derived mesenchymal stem cells differentiate into insulin, somatostatin, and glucagon expressing cells. Biochem Biophys Res Commun 2006; 341: 1135-1140.

24. Lechner A, Nolan AL, Blacken RA, Habener JF. Redifferentiation of insulin-secreting cells after in vitro expansion of adult human pancreatic islet tissue. Biochem Biophys Res Commun 2005; 327: 581-588.

25. Gershengorn MC, Hardikar AA, Wei C, Geras-Raaka E, Marcus-Samuels B, Raaka BM. Epithelial-to-mesenchymal transition generates proliferative human islet precursor cells. Science 2004; 306: 2261-2264.

26. Seeberger KL, Dufour JM, Shapiro AM, Lakey JR, Rajotte RV, Korbutt GS. Expansion of mesenchymal stem cells from human pancreatic ductal epithelium. Lab Invest 2006; 86: 141-153.

27. Chase LG, Ulloa-Montoya F, Kidder BL, Verfaillie CM. Islet-derived fibroblast-like cells are not derived via epithelial-mesenchymal transition from Pdx-1 or insulin-positive cells. Diabetes 2007; 56: 1-5

28. Morton RA, Geras-Raaka E, Wilson LM, Raaka BM, Gershengorn MC. Endocrine precursor cells from mouse islets are not generated by epithelial-to-mesenchymal transition of mature beta cells. Mol Cell Endocrinol 2007; 270: 87-93.

29. Weinberg N, Ouziel-Yahalom L, Knoller S, Efrat S, Dor Y. Lineage tracing evidence for in vitro dedifferentiation but rare proliferation of mouse pancreatic beta-cells. Diabetes 2007; 56: $1299-1304$

30. Atouf F, Park CH, Pechhold K, Ta M, Choi Y, Lumelsky NL. No evidence for mouse pancreatic beta-cell epithelial-mesenchymal transition in vitro. Diabetes 2007; 56: 699-702.

31. Kayali AG, Flores LE, Lopez AD, Kutlu B, Baetge E, Kitamura R et al. Limited capacity of human adult islets expanded in vitro to redifferentiate into insulin-producing beta-cells. Diabetes 2007; 56: 703-708.

32. Pittenger MF, Mackay AM, Beck SC, Jaiswal RK, Douglas R, Mosca JD et al. Multilineage potential of adult human mesenchymal stem cells. Science 1999; 284: 143-147.

33. Zuk PA, Zhu M, Mizuno $\mathrm{H}$, Huang J, Futrell JW, Katz AJ et al. Multilineage cells from human adipose tissue: implications for cell-based therapies. Tissue Eng 2001; 7: 211-228.

34. Denker AE, Nicoll SB, Tuan RS. Formation of cartilage-like spheroids by micromass cultures of murine $\mathrm{C} 3 \mathrm{H} 10 \mathrm{~T} 1 / 2$ cells upon treatment with transforming growth factor-beta 1. Differentiation 1995; 59: 25-34.

35. Ouziel-Yahalom L, Zalzman M, Anker-Kitai L, Knoller S, Bar Y, Glandt M et al. Expansion and redifferentiation of adult human pancreatic islet cells. Biochem Biophys Res Commun 2006; 341: 291-298.

36. Huang $\mathrm{H}$, Tang $\mathrm{X}$. Phenotypic determination and characterization of nestin-positive precursors derived from human fetal pancreas. Lab Invest 2003; 83: 539-547.

37. Lupi R, Dotta F, Marselli L, Del Guerra S, Masini M, Santangelo C et al. Prolonged exposure to free fatty acids has cytostatic and pro-apoptotic effects on human pancreatic islets: evidence that beta-cell death is caspase mediated, partially dependent on ceramide pathway, and Bcl-2 regulated. Diabetes 2002; 51: 1437-1444.

38. Gallo R, Zazzeroni F, Alesse $E$ Mincione $C$, Borello U, Buanne $P$ et al. REN: a novel, developmentally regulated gene that promotes neural cell differentiation. J Cell Biol 2002; 158: $731-740$.

39. Marselli L, Dotta F, Piro F, Santangelo C, Masini M, Lupi R et al. Th2 cytokines have a partial, direct protective effect on the function and survival of isolated human islets exposed to combined proinflammatory and Th1 cytokines. J Clin Endocrinol Metab 2001; 86: 4974-4978. 